\title{
L'autre face de la lune. Écrits sur le Japon de Claude
} Lévi-Strauss

\section{Raymond MAYER}

\section{(2) OpenEdition}

12 Journals

\section{Édition électronique}

URL : http://journals.openedition.org/jso/6458

DOI : $10.4000 /$ jso.6458

ISSN : $1760-7256$

\section{Éditeur}

Société des océanistes

\section{Édition imprimée}

Date de publication : 15 décembre 2011

Pagination : 448-450

ISBN : 978-2-85430-037-4

ISSN : 0300-953x

Référence électronique

Raymond MAYER, "L'autre face de la lune. Écrits sur le Japon de Claude Lévi-Strauss », Journal de la Société des Océanistes [En ligne], 133 | 2e semestre 2011, mis en ligne le 31 décembre 2011, consulté le 22 septembre 2020. URL : http://journals.openedition.org/jso/6458 ; DOI : https://doi.org/10.4000/ jso.6458

Ce document a été généré automatiquement le 22 septembre 2020.

(C) Tous droits réservés 


\title{
L'autre face de la lune. Écrits sur le Japon de Claude Lévi-Strauss
}

\author{
Raymond MAYER
}

\section{RÉFÉRENCE}

LÉVI-STRAUSS Claude, 2011. L'autre face de la lune. Écrits sur le Japon, Paris, Seuil, coll. La Librairie du xxie siècle, 10 photogr., $190 \mathrm{p}$.

1 Malgré le titre, cet ouvrage n'a rien à voir avec la sélénologie, mais bien avec la japonologie, en regroupant métaphoriquement un ensemble de réflexions censées présenter la face cachée de la culture japonaise. Préfacé par Junzo Kawada, anthropologue de l'université Kanagawa de Yokohama et traducteur de Tristes Tropiques en japonais, cet ouvrage posthume intéressera directement les Océanistes, car il ouvre et tourne le regard non seulement vers le Japon, mais embrasse d'un point de vue universel l'ensemble des relations entre civilisations riveraines. Peut-être même est-ce le livre où le regard porte le plus loin. Il s'agit moins de distance physique que de l'appréhension du caractère universel de tout geste, même le plus quotidien. En ce sens, il n'est plus question de tracer la courbure des espaces, mais plutôt celle des temps. Comme dans Anthropologie structurale, ce livre est un recueil d'articles, tous publiés antérieurement dans des revues diverses, à l'exception de l'entretien accordé par l'auteur à son préfacier, à Paris, à la télévision nippone NKH, en 1993.

2 Le premier texte, conférence prononcée en 1988 (à l'occasion de son cinquième et dernier voyage dans l'archipel nippon) et commanditée sur la «place de la culture japonaise dans le monde " évoque, entre autres sujets, la vie mythique rencontrée à l'état vivant aux îles Kyushu, situées au sud de l'archipel nippon.

«Tous [les] thèmes communs à l'Amérique indienne et à l'ancien Japon se rencontrent en Indonésie, et plusieurs ne sont bien attestés que dans ces trois régions. »

3 L'auteur en profite pour rappeler que : 
« durant les grandes glaciations et [...] il y a environ douze mille à dix-huit mille ans, le Japon fut uni au continent asiatique ; il formait alors un long promontoire incurvé vers le nord [...] l'Insulinde (c'est-à-dire l'ensemble des îles comprises entre Taïwan et l'Australie d'une part, la Nouvelle-Guinée et la péninsule malaise d'autre part) était en majeure partie reliée à la terre ferme ; enfin, des terres émergées larges d'environ mille kilomètres joignaient l'Asie et l'Amérique sur l'emplacement actuel du détroit de Béring. En bordure du continent, une sorte de boulevard terrestre permettait aux hommes, aux objets, aux idées, de circuler librement depuis l'Indonésie jusqu'à l'Alaska, en passant par les côtes de la Chine, la Corée, la Mandchourie, la Sibérie du Nord... À différents moments de la préhistoire, ce vaste ensemble dut être le théâtre de mouvements de populations dans les deux sens. Mieux vaut donc renoncer à chercher des points d'origine. Selon toute vraisemblance, les mythes constituent un patrimoine commun dont nous recueillons çà et là des fragments » $(2011: 26)$.

Bonne manière de réinstaller le Japon en Océanie et dans l'océanisme! La question mérite sans doute d'être posée et traitée comme telle. Dans la perspective de la conférence, ce sont cependant les aspects plus classiques du Japon culinaire, plastique, musical, littéraire, philosophique et linguistique qui ont été évoqués pour répondre aux souhaits de ses auditeurs. Quelques fortes inspirations étayent un texte certes conventionnel, mais dont les lecteurs avertis retireront quelque miel.

5 Le deuxième texte "La face cachée de la lune », qui donne son titre à l'ouvrage tout entier, date de 1979 et correspond à la séance de clôture d'un colloque organisé à Paris sur les études japonaises en France. Comme le précédent - mais, compte tenu de la chronologie, on doit dire: antérieurement à lui -, ce texte relève quelques aspects saillants de la culture japonaise, mais composé après le premier voyage au Japon, il est beaucoup plus superficiel dans son analyse, et on comprend que l'éditeur l'ait mis en seconde position dans la publication, dérogeant au principe de l'ordre chronologique. $\mathrm{Au}$ retour du premier voyage, Lévi-Strauss n'a encore rien à dire sur la musique, ses références sont Malraux et Ingres, alors dans la conférence de 1988, la comparaison des auteurs japonais et français porte sur le Rousseau de La nouvelle Héloïse et le Chateaubriand des Mémoires d'outre-tombe. Il est difficile d'échapper aux conventions protocolaires qui enrobent ce type de discours.

6 Le troisième texte crée l'échappée belle en courant derrière "Le lièvre blanc d'Inaba ». Il s'agit de notes publiées en 2002 sur la comparaison des versions d'un conte animalier qui se retrouve au Japon et en Amérique du Nord. Et on doit dire, en dépassant les perspectives tracées par Claude Lévi-Strauss lui-même, dans les cinq continents. L'analyse en reste à un niveau assez empirique, se contentant de trouver des correspondances entre des versions des continents respectifs.

7 Le quatrième texte (pp.91-108) reprend un article plus connu et publié en 1987. «Hérodote en mer de Chine » est en effet la réaction intellectuelle suscitée chez LéviStrauss par sa fréquentation des îles Ryûkyû, où la récitation d'une mélopée locale fait surgir chez lui le souvenir scolaire de l'histoire des deux fils de Crésus chez Hérodote, ainsi que celle des oreilles d'âne du roi Midas chez Ovide. Pour le premier thème, dans la version japonaise, le prince muet, déshérité du fait de son infirmité, recouvre la parole en empêchant son plus fidèle serviteur de se suicider. Recouvrant la parole, il récupère aussi la succession au trône. Dans la version grecque, le fils muet empêche un soldat ennemi de tuer son père Crésus en lui criant de ne pas passer à l'acte et retrouve ainsi la parole jusqu'à sa mort. Même similitude de thème narratif dans le récit du roi japonais qui coiffe une sorte du turban pour cacher ses longues oreilles poilues, et dont le secret est éventé 
par son coiffeur et diffusé depuis lors par les sifflements du vent dans les bambous ou les palmes du rivage. Dans les deux cas, Lévi-Strauss retient la thèse diffusionniste des thèmes narratifs, véhiculés selon lui par des traditions bouddhistes allant tant vers l'Occident que vers l'Orient. Il n'en retire ainsi aucun avantage pour une lecture structurale des corpus mis en présence.

Le cinquième texte, certainement l'un des plus beaux du livre, porte sur l'œuvre du peintre-calligraphe Sengaï (1750-1830). Ce maître s'inscrit dans la tradition des cérémonies du thé qui utilisaient les ustensiles les plus grossiers et les plus humbles: bols de paysans aux matières rugueuses et aux formes irrégulières, ce qui s'appela "l'art de l'imparfait» (p. 113). Sous cette expression se cache un véritable éloge de l'inachevé et de l'irrégulier, ce qui, sous la plume de Lévi-Strauss, peut paraitre comme un véritable déni de la rationalisation qui l'a guidé tout au long de son œuvre, sauf dans ses dernières publications comme par exemple Regarder écouter lire (1993).

Le très bref texte qui suit (pp. 127-132) est une préface à la réédition, en 1998, d'un livre de l'an 1585 écrit par le père jésuite Luis Frois, à l'occasion de sa visite du Japon. "Apprivoiser l'étrangeté » est un habile plaidoyer pour la symétrie égalitaire, entendons par là le constat récurrent que «les Japonais font beaucoup de choses de façon exactement contraire à ce que les Européens jugent naturel et convenable » (p.128). Ce qui ne signifie pas que les cultures soient inégales, mais au contraire opposables sur un pied d'égalité. "Apprivoiser l'étrangeté » est donc une stratégie d'approche respectueuse de l'altérité.

Sous le titre un tantinet provocateur "La danse impudique de Ame no Uzume " (pp.133-147), Lévi-Strauss se fait plaisir à traquer et poursuivre un même thème mythique dans deux cultures aussi éloignées dans le temps et l'espace que celle de l'Égypte pharaonique du deuxième millénaire avant notre ère et celle du Japon 3000 ans plus tard. La conclusion selon Lévi-Strauss est que « s'il faut traiter les similitudes avec réserve, en revanche les différences peuvent nourrir la réflexion » (p. 146).

11 Le huitième texte est la préface à la dernière édition, en 2001, de Tristes Tropiques en langue japonaise. Cette préface fut intitulée «Un Tokyô inconnu ». S'accrochant au souvenir d'un Tokyô fluvial sillonné lors de son dernier voyage de 1986, elle s'arrête principalement sur la conception du travail dans des cultures différentes.

Vient enfin (pp. 157-181) la transcription d'une partie de l'entretien filmé par la chaîne de télévision japonaise NHK entre Junzo Kawada et Claude Lévi-Strauss, à Paris, en 1993. Celui-ci reprend de manière dialoguée la diversité des thèmes qui animent l'ensemble du livre: mythes, gastronomie, symétries culturelles. Un cahier de dix photographies de la collection du professeur Kawada (dont sept en couleurs) y a été inséré, illustrant les déplacements de Lévi-Strauss au Japon et en France de 1977 à 1997.

Le montage des différentes pièces à thèmes de ce livre dédié à la culture japonaise, ou du moins à la vision que s'en était donnée Claude Lévi-Strauss, ajoute évidemment à l'imposant testament intellectuel que lègue son auteur, mais elle documente surtout de manière inédite la partie non américaniste de son œuvre. Le projet éditorial avait donc toute sa raison d'être, d'autant qu'il ajoute le Pacifique Nord aux terrains constitutifs de ses analyses. 